\title{
First identification and characterisation of Brachyspira hyodysenteriae in pigs in Hong Kong
}

\author{
Kittitat Lugsomya ${ }^{1}$, Friederike Zeeh ${ }^{1 *}$ (D) Tom La², Nyree Phillips ${ }^{2}$ and David J. Hampson ${ }^{1,2}$
}

\begin{abstract}
Swine dysentery (SD) is an important endemic disease of pigs throughout the world. The most common aetiological agent is the anaerobic intestinal spirochaete Brachyspira hyodysenteriae. The related spirochaete Brachyspira pilosicoli causes a milder form of colitis. We report the first isolation of B. hyodysenteriae and B. pilosicoli from a pig farm in Hong Kong. Faecal samples containing mucus or fresh blood were collected from the ground where finisher pigs had just been loaded into a truck for transport to the abattoir. The samples were subjected to selective anaerobic culture and PCR for B. hyodysenteriae and B. pilosicoli, and two isolates of both species were obtained. The $B$. hyodysenteriae isolates showed clinical resistance to tylosin and lincomycin, whilst the $B$. pilosicoli isolates were resistant to tylosin and showed intermediate susceptibility to lincomycin. The B. hyodysenteriae isolates were subjected to multilocus sequence typing and a single previously undescribed sequence type (ST250) was identified. Disease was not recorded in other pigs on the farm, but it may have been masked by the use of antimicrobials. Further work is required to examine the distribution of these two pathogens in this and other farms in Hong Kong and in adjoining mainland China.
\end{abstract}

Keywords: Swine dysentery, Multilocus sequence typing, Epidemiology, Antimicrobial susceptibility, Minimum inhibitory concentrations, Brachyspira pilosicoli, Spirochaetes

Swine dysentery (SD) is an infectious mucohaemorrhagic colitis of pigs which mainly occurs in the grower and finisher phases of production. Uncontrolled SD can cause a severe economic impact through reduced growth rates, mortalities and disruption of pig trade [1]. The most common and widespread aetiological agent of SD is the anaerobic intestinal spirochaete Brachyspira hyodysenteriae, although in some regions the related species Brachyspira hampsonii and Brachyspira suanatina also may cause SD [2]. Brachyspira pilosicoli is another species that can cause a milder form of colitis in pigs and in other species [3]. In Hong Kong Special Administrative Region of the People's Republic of China there are 43 small pig farms with a median of about 200 sows. To date there have been no scientific reports of SD in

\footnotetext{
* Correspondence: friederike.zeeh@cityu.edu.hk

${ }^{1}$ Department of Infectious Diseases and Public Health, Jockey Club College of Veterinary Medicine and Life Sciences, City University of Hong Kong, Kowloon Tong Hong Kong, Hong Kong SAR

Full list of author information is available at the end of the article
}

these farms. This is of interest because of the proximity to the huge swine population in adjoining mainland China, and the reports of SD caused by B. hyodysenteriae there and in Taiwan $[4,5]$. Hong Kong pig farmers have imported replacement pigs from both countries. In this short communication, we describe the isolation and characterisation of $B$. hyodysenteriae and B. pilosicoli from pig faeces on a farm in Hong Kong.

A faecal sample containing mucus and another with a spot of fresh blood were observed on the ground in a pig farm in the New Territories of Hong Kong at a site where fattening pigs had just been loaded into a truck for transportation to the abattoir. As the farmer was concerned about the appearance of the faeces, he collected these and samples from seven other healthy looking finisher pigs. Two months later the farmer collected faecal samples from another 20 finisher pigs, although none of these samples had an abnormal appearance.

(C) The Author(s). 2019 Open Access This article is distributed under the terms of the Creative Commons Attribution 4.0 International License (http://creativecommons.org/licenses/by/4.0/), which permits unrestricted use, distribution, and reproduction in any medium, provided you give appropriate credit to the original author(s) and the source, provide a link to the Creative Commons license, and indicate if changes were made. The Creative Commons Public Domain Dedication waiver (http://creativecommons.org/publicdomain/zero/1.0/) applies to the data made available in this article, unless otherwise stated. 
The samples were sent to the Veterinary Diagnostic Laboratory at City University of Hong Kong. They were subjected to anaerobic culture for Brachyspira species using selective Trypticase Soy Agar (TSA) containing 5\% defibrinated ovine blood, $400 \mu \mathrm{g} / \mathrm{ml}$ of spectinomycin and $25 \mu \mathrm{g} / \mathrm{ml}$ each of colistin and vancomycin (SigmaAldrich) [6]. The plates were incubated at $37^{\circ} \mathrm{C}$ for 5 days in an anaerobic atmosphere generated using the Anaergen $^{\text {tw }}$ system (Oxoid). Zones of haemolysis around the inoculated area indicated growth, and confirmation that spirochaetes were present was obtained by resuspending surface growth and subjecting it to Gram staining before examining at 1000 times magnification. Areas of spirochaetal growth were sub-cultured on selective TSA and then transferred to TSA not containing antimicrobials to grow the purified spirochaetes for further examination. For species identification, the surface growth was subjected to a duplex PCR that is specific for B. hyodysenteriae and B. pilosicoli [7].

The two initial samples from the floor of the loading area both yielded strongly haemolytic and weakly haemolytic spirochaetal growth on selective TSA. Spirochaetes were not cultured from the other seven samples taken from fattening pigs at that time, or from the 20 samples that were collected 2 months later. Using the species-specific PCR, the strongly haemolytic growth was identified as $B$. hyodysenteriae and the weakly haemolytic growth as $B$. pilosicoli. Two isolates that were identified as $B$. hyodysenteriae were designated as C4B9 and $\mathrm{C} 5 \mathrm{~B} 2$ and two identified as B. pilosicoli were named C4B3 and C5B8.

High molecular weight DNA was extracted from the B. hyodysenteriae isolates using the DNeasy Blood and Tissue Kit (Qiagen) according to the manufacturer's instructions. Multilocus sequence typing (MLST) was conducted using the seven loci used for in the Brachyspira MLST scheme $[8,9]$. The sequences were submitted to the PubMLST site (https://pubmlst.org/brachyspira/), and sequence types (STs) were assigned within the $B$. hyodysenteriae species-specific MLST scheme.

Using MLST, both B. hyodysenteriae isolates were allocated to sequence type 250 (ST250). This is a newly described ST which was defined as singleton. Its nearest neighbour is ST22 with which it shares 4 of 7 loci, and which contains Australian isolates from the 1980s. MLST was not conducted on the B. pilosicoli isolates because the cultures were lost following storage.

The susceptibility of the isolates and control strains to tylosin, lincomycin and tiamulin was tested by agar dilution following Clinical and Laboratory Standards Institute (CSLI) guidelines [10]. Control strains were $B$. hyodysenteriae strains $\mathrm{B}^{2 \mathrm{~T}}$ and $\mathrm{B} 204$, and B. pilosicoli strains 95/1000 and WesB. Minimum inhibitory concentrations (MICs) of the isolates and control strains to the three antimicrobial agents were recorded as the lowest concentration which inhibited growth of the bacteria on the plates. The susceptibility of the isolates was interpreted following published breakpoints for establishing clinical resistance in agar dilution testing in Brachyspira species. For tiamulin, the CSLI breakpoint of $>0.25 \mu \mathrm{g} / \mathrm{ml}$ was used [10]. For tylosin and lincomycin, MICs of $>$ $16 \mu \mathrm{g} / \mathrm{ml}$ and $>1 \mu \mathrm{g} / \mathrm{ml}$ were used, respectively. These values followed Rønne and Szancer's criteria [11], as CSLI breakpoints for these two antimicrobials are not available for Brachyspira species. The MIC values of the Hong Kong isolates and the control strains of both species are shown in Table 1. All the Hong Kong strains were recorded as being susceptible to tiamulin and resistant to tylosin. Furthermore, the $B$. hyodysenteriae isolates were resistant to lincomycin, but the $B$. pilosicoli isolates showed intermediate susceptibility.

This is the first identification of B. hyodysenteriae and of $B$. pilosicoli in pigs in Hong Kong. The single ST of $B$. hyodysenteriae suggested that only one strain might be present on the farm. From MLST data, this strain was different from strains previously identified in other parts of the world. Due to the limited number of analysed isolates, the meaning of this finding is unclear. Either this B. hyodysenteriae has been introduced into Hong Kong through importation of live pigs, or there might be a local population of Brachyspira. Here, the original source of infection remains unclear.

Spirochaetes were not isolated from other pigs on the farm, and there was no sign of disease other than the two atypical faecal samples derived from finisher pigs. On subsequent discussion, the farmer revealed that he injected any pigs with diarrhoea using a quinoxaline-N, $\mathrm{N}$-dioxide antibacterial agent. Earlier he had been

Table 1 Sequence types and their interpreted susceptibility and minimum inhibitory concentrations of the eight Brachyspira isolates/strains

\begin{tabular}{|c|c|c|c|c|}
\hline \multirow[t]{2}{*}{ Isolate/strain } & \multirow{2}{*}{$\begin{array}{l}\text { Species- } \\
\text { specific } \\
\text { sequence } \\
\text { type }\end{array}$} & \multicolumn{3}{|c|}{ Susceptibility (MIC in $\mu \mathrm{g} / \mathrm{ml}$ ) } \\
\hline & & Tylosin & Lincomycin & Tiamulin \\
\hline B. hyodysenteriae C4B8 & 250 & $\mathrm{R}(>16)$ & $\mathrm{R}(>72)$ & $S(<0.063)$ \\
\hline B. hyodysenteriae C5B9 & 250 & $R(>16)$ & $R(>72)$ & $S(<0.063)$ \\
\hline B. hyodysenteriae $B 78^{\top}$ & 56 & I (4) & $S(<2)$ & $S(<0.063)$ \\
\hline B. hyodysenteriae B204 & 54 & $R(>16)$ & I (36) & $S(<0.063)$ \\
\hline B. pilosicoli C4B3 & NK & $R(>16)$ & I (16) & $S(<0.063)$ \\
\hline B. pilosicoli C4B8 & NK & $R(>16)$ & I (16) & $S(<0.063)$ \\
\hline B. pilosicoli 95/1000 & 82 & $S(<0.5)$ & I (36) & $S(<0.063)$ \\
\hline B. pilosicoli WesB & 68 & $S(<0.5)$ & $S(<2)$ & $S(<0.063)$ \\
\hline
\end{tabular}

The isolates C4B8, C5B9, C4B3 and C4B8 originated from a pig herd in Hong Kong Special Administrative Region. Minimum inhibitory concentrations (MIC) were determined by agar dilution and interpreted according to [11] for tylosin, lincomycin and to [10] for tiamulin.

$N K$ not known, $S$ susceptible, I intermediate, $R$ resistant 
injecting pigs with a combination of lincomycin and spectinomycin (concentration and dosage unknown). Tiamulin had not been used on the farm. The farmer sourced his antimicrobials directly from mainland China. These comments suggested that although disease was occasionally seen it was being masked by the use of antimicrobials. The isolates showed elevated MICs to tylosin and to lincomycin in the case of B. hyodysenteriae, but not to tiamulin, and this reflected the antimicrobial usage on the farm.

High MICs to all three antimicrobials have been recorded in B. hyodysenteriae and B. pilosicoli isolates in nearby Taiwan, and attributed to frequent use of these antimicrobials in pig production there [5].

Further work is required to assess the extent of infection in the farm from which the isolates were recovered, as well as to determine whether infection with pathogenic Brachyspira species occurs in other pig farms in Hong Kong. Both species also can infect chickens [12, 13], so examination of layer flocks in Hong Kong for infection also is warranted. Furthermore, more $B$. hyodysenteriae isolates should be characterised for better understanding of their epidemiology and control measures of SD.

\section{Abbreviations}

Hong Kong SAR: Hong Kong Special Administrative Region; MIC: Minimum inhibitory concentrations; MLST: Multilocus sequence typing:

PCR: Polymerase chain reaction; SD: Swine dysentery; ST: Sequence type;

TSA: Trypticase Soy Agar

\section{Acknowledgments}

Not applicable.

\section{Authors' contributions}

$\mathrm{KL}$ and DH collected the samples; KL, NP and TL analysed the samples and data. DH and FZ wrote the manuscript. All other authors revised the manuscript. All authors read and approved the final manuscript.

\section{Funding}

The cost of the diagnostic investigation was supported by City University of Hong Kong (project number 9676006).

\section{Availability of data and materials}

Not applicable.

\section{Ethics approval and consent to participate}

None required.

\section{Consent for publication}

Not applicable.

\section{Competing interests}

The authors declare that they have no competing interests.

\section{Author details}

'Department of Infectious Diseases and Public Health, Jockey Club College of Veterinary Medicine and Life Sciences, City University of Hong Kong, Kowloon Tong Hong Kong, Hong Kong SAR. ${ }^{2}$ School of Veterinary and Life Sciences, Murdoch University, Murdoch, Western Australia 6150, Australia.
Received: 1 September 2019 Accepted: 21 October 2019

Published online: 04 December 2019

\section{References}

1. Hampson DJ, Burrough ER. Swine dysentery and Brachyspiral colitis. In: Zimmerman JJ, Karriker LA, Ramirez A, Schwartz KJ, Stevenson GW, Zhang J, editors. Diseases of swine. 11th ed. Hoboken: Wiley-Blackwell; 2019. p. 951-70.

2. Burrough ER. Swine Dysentery: Etiopathogenesis and diagnosis of a reemerging disease. Vet Pathol. 2016. Cited 2016 Jun 13. https://doi.org/10. 1177/0300985816653795.

3. Hampson DJ. The spirochete Brachyspira pilosicoli: enteric pathogen of animals and man. Clin Microbiol Rev. 2018;31(1):e00087-17.

4. Qi X, Xu F, Zhang W, Ge F, Shen L, Wang J, et al. Isolation and identification of Brachyspira hyodysenteriae and pathological examination of swine dysentery. Chinese J Prev Vet Med. 2017;39(1):42-4.

5. Yeh JC, Lo DY, Chang SK, et al. Antimicrobial susceptibility patterns of Brachyspira species isolated in Taiwan. Microb Drug Resist. 2018;24:685-92.

6. Jenkinson SR, Wingar CR. Selective medium for the isolation of Treponema hyodysenteriae. Vet Rec. 1981;109:384-5.

7. La T, Phillips ND, Hampson DJ. Development of a duplex PCR assay for the detection of Brachyspira hyodysenteriae and Brachyspira pilosicoli in pig feces. J Clin Microbiol. 2003;41:3372-5.

8. Råsbäck T, Johansson K-E, Jansson DS, et al. Development of a multilocus sequence typing scheme for intestinal spirochaetes of the genus Brachyspira. Microbiol. 2007:153:4074-87.

9. La T, Phillips ND, Harland BL, et al. Multilocus sequence typing as a tool for studying the molecular epidemiology and population structure of Brachyspira hyodysenteriae. Vet Microbiol. 2009;138:330-8.

10. CLSI VETO6. Methods for antimicrobial susceptibility testing of infrequently isolated or fastidious bacteria isolated from animals. 1st ed: Clinical and Laboratory Standards Institute; 2017.

11. Rønne H, Szancer J. In vitro susceptibility of Danish field isolates of Treponema hyodysenteriae to chemotherapeutics in swine dysentery (SD) therapy: interpretation of MIC results based on the pharmacokinetic properties of the antibacterial agents. Proc Int Cong Pig Vet Soc. 1990:11:126.

12. Stephens $C P$, Hampson DJ. Experimental infection of broiler breeder hens with the intestinal spirochaete Brachyspira (Serpulina) pilosicoli causes reduced egg production. Avian Pathol. 2002;31:169-75.

13. Feberwee A, Hampson DJ, Phillips ND, et al. Identification of Brachyspira hyodysenteriae and other pathogenic Brachyspira species in chickens from laying flocks with diarrhea or reduced production or both. J Clin Microbiol. 2008:46:593-600.

\section{Publisher's Note}

Springer Nature remains neutral with regard to jurisdictional claims in published maps and institutional affiliations.
Ready to submit your research? Choose BMC and benefit from:
- fast, convenient online submission
- thorough peer review by experienced researchers in your field
- rapid publication on acceptance
- support for research data, including large and complex data types
- gold Open Access which fosters wider collaboration and increased citations
- maximum visibility for your research: over $100 \mathrm{M}$ website views per year
At BMC, research is always in progress.
Learn more biomedcentral.com/submission 